\title{
POWER SYSTEM STABILITY IMPROVEMENT USING (SSSC)
}

\author{
Tarek Mahmoud \\ Electrical Engineering Department, Faculty of Engineering, AL-Azhar University \\ E-mail: tarekmahmoudn1967@hotmail.com
}

\begin{abstract}
In this paper the impact of one type of Flexible AC Transmission Systems (FACTS) devices which is called Static Series Synchronous Compensator (SSSC) for improving power system stability is developed. The optimal location of (SSSC) is determined related to deregulated electricity market to reduce system losses and congestion of the transmission line, hence increasing maximum load ability of the system. The congested line based on optimal power flow (OPF) tool to find local marginal price (LMP) difference is determined. A list is formed based on the magnitude of the difference in (LMPs) to find the most congested lines. For each line in the priority list the continuation power flow (CPF) is determined with (SSSC) in that line, the best location of (SSSC) is the one where by placing (SSSC) gives highest maximum loading point. The results showed that proposed location of (SSSC) in congested line give higher maximum loading point and improve system dynamic performance. The study is illustrated on IEEE 14-bus system, based on Power System Analysis Toolset (PSAT).
\end{abstract}

KEYWORDS: Facts Flexible Ac Transmission Systems, Sssc (Series Synchronous Compensator, Opf (Optimal Power Flow, Lmp (Local Marginal Price , and Cpf, Continuation Power Flow

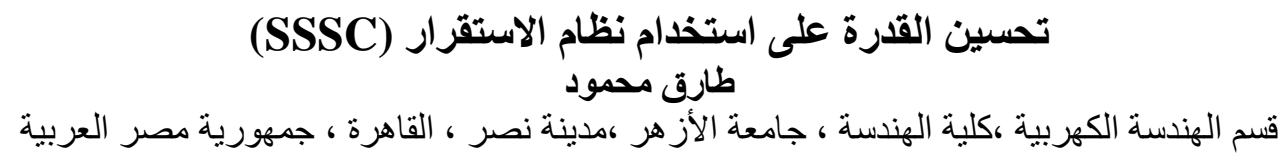

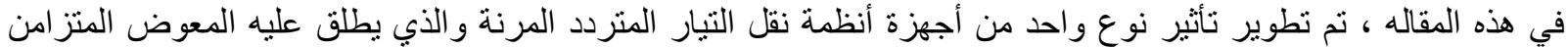

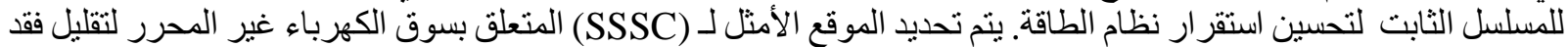

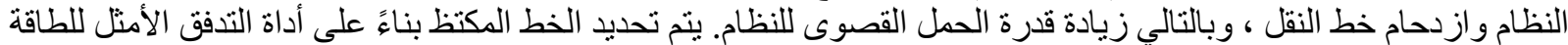

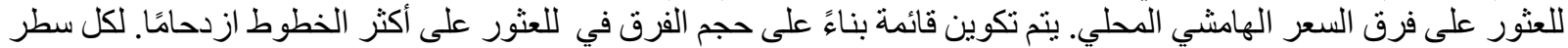

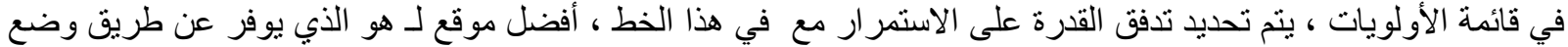

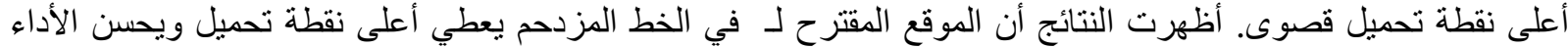
الديناميكي للنظام. تم توضيح الدر اسة على نظام ، استنادًا إلى مجمو عة ألى أدو ات تحليل نظام الطاقة .

الكلمات المفتاحية : المتزامن، أداة التدفق الأمثل ، السعر الهامشى المحلي، الأداء الديناميكي للنظام ، استمرار تدفق الطاقة.

1. INTRODUCTION:

The existing transmission networks often operate close to their limits. Hence, has an overall effect of deteriorating voltage profiles and decreasing system stability and security. This overall situation requires the review of traditional transmission methods and practices, and the creation 
of new concepts, which would allow the use of existing generation and transmission lines up to their full capabilities without reduction in system stability and security. Thanks to a rapid development of power electronics and semiconductor technologies in the last two decades, a new family of devices with a common name of flexible AC transmission systems (FACTS) is becoming available. Coupled with advanced monitoring and control algorithms, (FACTS) can help utilities to nudge power flows in desired directions and allow practically complete utilization of the capacity of transmission elements up to their thermal limits. By using (FACTS) controllers one can control the variables such as voltage magnitude and phase angle at chosen bus and line impedance [1]. Installations of multiple FACTS devices offer a great opportunity concerning the flexibility of system-wide power flow control. However, their control actions may cause mutual negative effects which affect the system security [2]. It is important to choose a suitable location and optimal size of (FACTS) to reach the required goals because of their considerable costs. There are several methods for finding optimal Locations of (FACTS) devices in both vertically Integrated and unbundled power systems. In [3], a sensitivity approach based on line loss has been proposed for placement of series capacitors, phase shifters and static VAR (Volt AmpereReactive) compensators. Other works in optimal power flow with (FACTS) devices $[4,5]$ have used optimization with different objective functions. In [6,7], the optimal locations of (FACTS) devices are obtained by solving the economic dispatch problem plus the cost of these devices if all lines, initially, have these devices.

This paper develops optimal location of (SSSC) To increase the maximum load ability. An approach of obtaining location of (FACTS) based on finding congested line by using method of (LMP) found in [8].Using (CPF) tool [9] to find maximum load ability for selected congested lines with one device of (FACTS), the best location which gives highest maximum loading point. Dynamic limits, which are typically the loading levels at which the system presents oscillatory instabilities associated with Hopf bifurcations and critical eigenvalues, are also depicted.

This paper is organized as follows Section 2 presents a Model of (SSSC) as one of the (FACTS) devices which is a modern choice that utilizes advance power electronics technology. In section 3.The Continuation Power Flow method is discussed then, section 4 describe the methodology, which is tested on a 14-bus test system. In Section 5 The simulation results are presented and discussed briefly after inserting (SSSC) in selected location during time domain simulation with three phase fault at selected bus. In the last section 6 , some relevant conclusions are given.

\section{SSSC Model}

ASSSC is an electrical device for providing fast-acting reactive power compensation on high voltage transmission networks and it can contribute to improve the voltages profile in the transient state[10]. The SSSC is generally connected in series with the transmission line. SSSC comprises voltage source converters And a DC capacitor. The injected voltage of the coupling transformer Vs is perpendicular to the line current. SSSC is used for controlling active and reactive power in transmission line one side of the converter. It is connected to AC system and other side is connected to a capacitor and battery. It assumes DC source as battery installation to allow active as well as reactive power exchanges with the AC system.Fig.1. shows the block diagram for a TCSC controller operating under current control [11]. The general structure of the stability controller is shown in Fig.2. [12]. It Consists of a washout filter, a dynamic compensator, and a limiter. The washout filter is used to avoid a controller response to the dc offset of the input signal. The dynamic compensator consists of two (or more) lead-lag blocks to provide the necessary phase-lead characteristics. Finally, the limiter is used to improve controller response to large deviations in the input signal. 


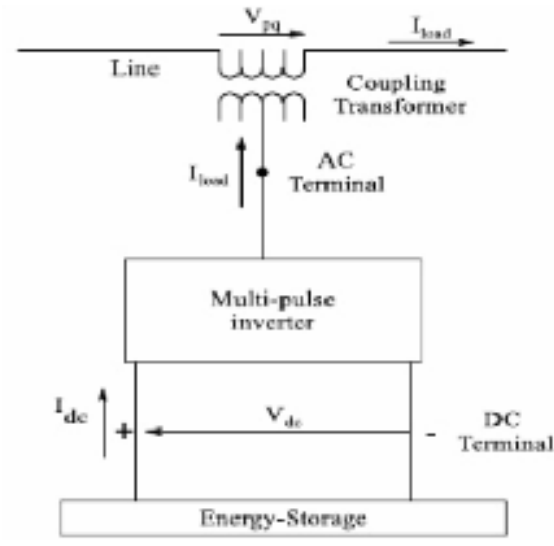

Fig.1. Basic (SSSC) structure.

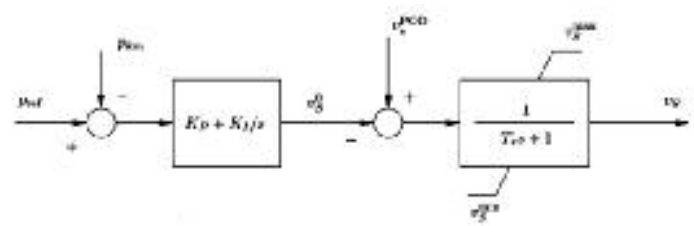

Fig.2 Block diagram of the (SSSC) stability control loop.

\section{CONTINUATION POWER FLOW METHOD}

The Continuation Power Flow is to find the continuity of power flow solution for a given load change .Continuation methods overcome certain difficulties of successive power flow solution methods, as they are not based on a particular system model, and allow the user to trace the complete voltage profile by automatically changing the value of loading parameter $\lambda$; without having to worry about singularities of system equations. The strategy used in Continuation method is shown in Fig.3. [13]. It starts from a known solution and uses a tangent predictor to estimate a subsequent solution corresponding to a different value of the load parameter. This estimate is then corrected using the same Newton-Raphson (NR) technique employed by a conventional power flow. A detailed description of these techniques is referred to [14].

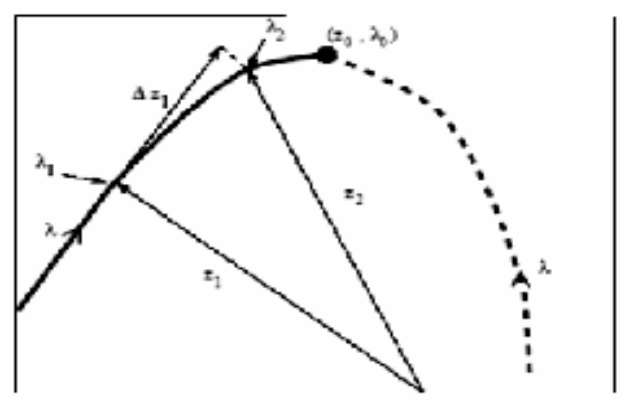

Fig.3. Continuation power flow (CPF) method

Dynamic voltage stability is analyzed by monitoring the Eigen values of the linearized system as a power system is progressively loaded. When the $\lambda$ parameter varies, the equilibrium points of the dynamic system also vary accordingly, and so do the Eigen values of the corresponding state matrix as shown in Fig.4. Equilibrium points are asymptotically stable if all the Eigen values have negative real parts. The point where a complex conjugate pair of Eigen values reaches the imaginary axis with respect to changes in $\lambda$ is known as Hopf Bifurcation point. Which is a local bifurcation in which a fixed point of a dynamical system loses stability as a pair of complex 
conjugate Eigen values of the linearization around the fixed point cross the imaginary axis of the complex plane [15-16] If this dynamic problem is studied using gradual changes it can be viewed as Hopf Bifurcation problem. Thus, by predicting these types of bifurcations well in advance, a possible dynamic instability problem may be avoided.

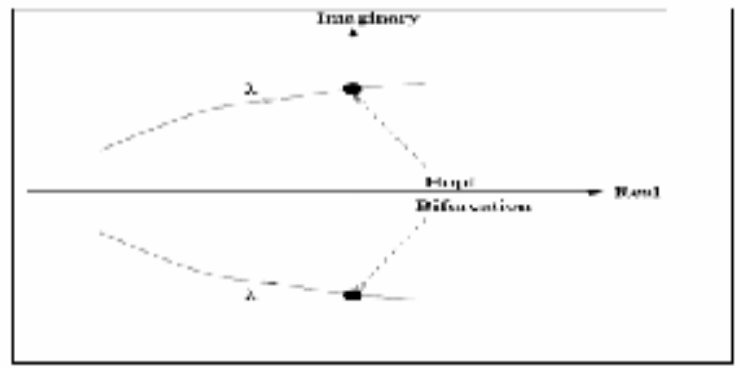

Fig.4. Hopf Bifurcation Point

\section{LOCATION MARGINAL PRICE [LMP] METHOD}

The main concept behind the (LMP) difference method is to make use of the economic signal given as (LMP) to select the congested lines to manage congestion and hence increasing loading stability limit. It is motivated from the fact that (LMP) contains significant information regarding level of congestion in the system [16]. (LMP) is composed of three components, an energy component, a loss component and a congestion component. For a meshed system, loss component is generally small. Hence, the difference in (LMP) between two buses gives direct hint regarding the level of congestion in that line [17].

\section{SIMULATION RESULTS}

\subsection{Test system}

The IEEE14- bus test system is used as in Fig.5 which depicts the single line diagram of the IEEE 14 bus test system used in this paper. It consists of 14 buses, 20 branches, 3 transformers, and 5 synchronous machines. Power system analysis toolbox software (PSAT), which has many features including power flow and continuation power flow, is used [19]. Using continuation power flow feature of PSAT, voltage stability of the test system, is investigated.

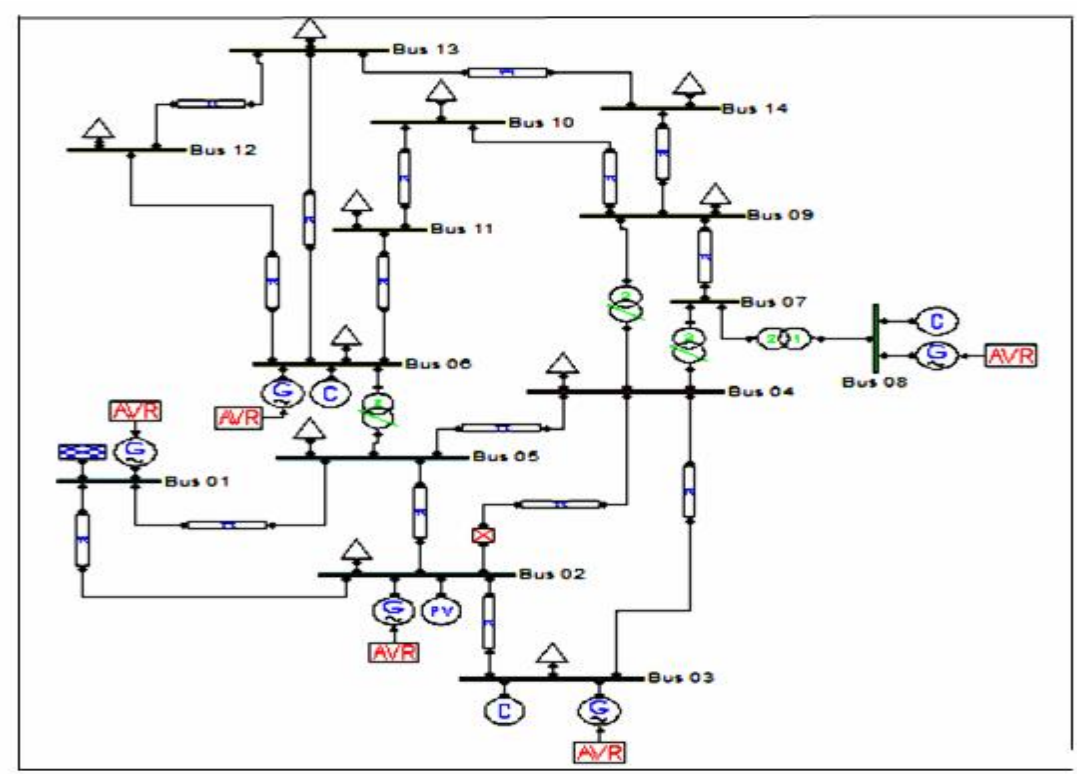

Fig.5The IEEE 14 bus test system 


\subsection{SIMULATION WITH (SSSC)}

In the test system the optimal location of (SSSC) is connected in series with line 5-6 based on (LMPs) difference method. Also, Single emergency were given in the system and it is observed as the severity of the emergency decreases, the static margin (SM) increases. 1-2 contingence line was the most severe case followed by 5-6, 7-9, 3-2 and 1-5 (these being top five) based on (CPF) method. Table 1.and Fig.6 illustrates the dynamic margin (DM) and static margin (SM) associated with P-V curves for the system with (SSSC), line 7-9 and line 5-1 outages. In these curves, Hopf Bifurcation (HB)

points, which were obtained through eigen value analysis, are also depicted. The maximum loading point in this condition is $\lambda=3.4587$ as shown in table1. P-V curves at bus\# 14 with (SSSC) for normal operating and two selected outage lines is shown in fig 6.To study the behavior of the system under large perturbations, a time Domain simulation and eigenvalue computation were performed for a line 5-1 outage at the operating point defined by $\lambda=1.6$ where three phase fault happens at Bus 5 at $\mathrm{t}=1$. s. The fault is cleared at $2.08 \mathrm{~s}$ by opening the faulted line. From Fig. 7 to Fig.9 show the corresponding time domain simulation results.

Table 1: Dynamic Margins and Static Margins for System with SSSC

\begin{tabular}{|c|c|c|c|}
\hline & $\begin{array}{c}\text { Normal } \\
\text { operating }\end{array}$ & $\begin{array}{c}\text { Line } \\
\text { outage } \\
7-9\end{array}$ & $\begin{array}{c}\text { Line } \\
\text { outage } \\
5-1\end{array}$ \\
\hline SM & 3.45 & 2.3 & 2.04 \\
\hline DM & 1.923 & 1.808 & 1.64 \\
\hline
\end{tabular}

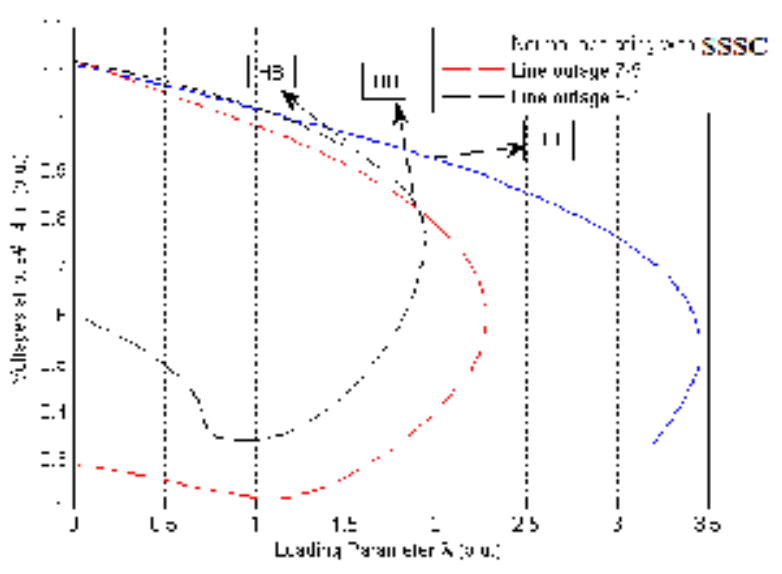

Fig.7: Active power at bus 8 due to line 5-1 outage at $\lambda=1.6$ p.u for system with (SSSC)
Fig.6 P-V curves at bus\# 14 with (SSSC)

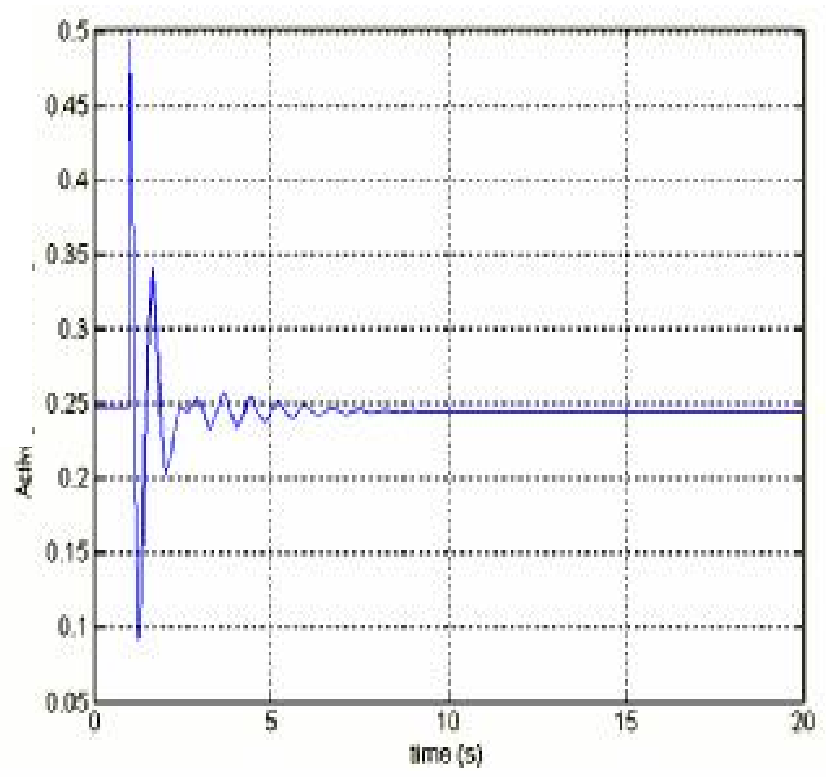


POWER SYSTEM STABILITY IMPROVEMENT USING (SSSC)

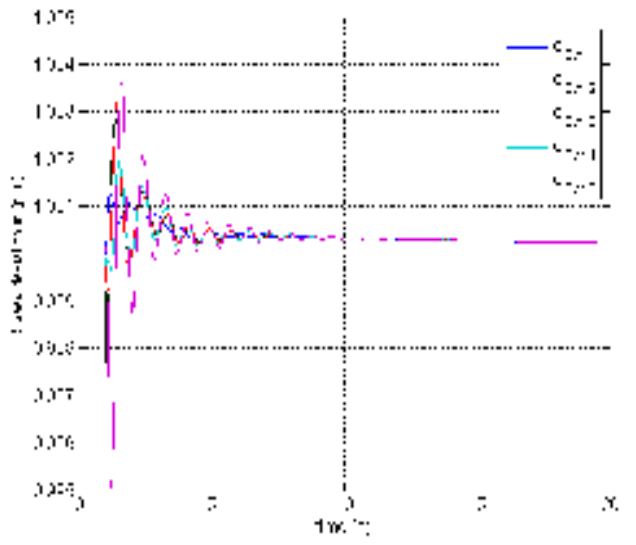

Fig.8 Generator speed oscillation due to line 5-1 outage at $\lambda=1.6$ p.u.for system with (SSSC)

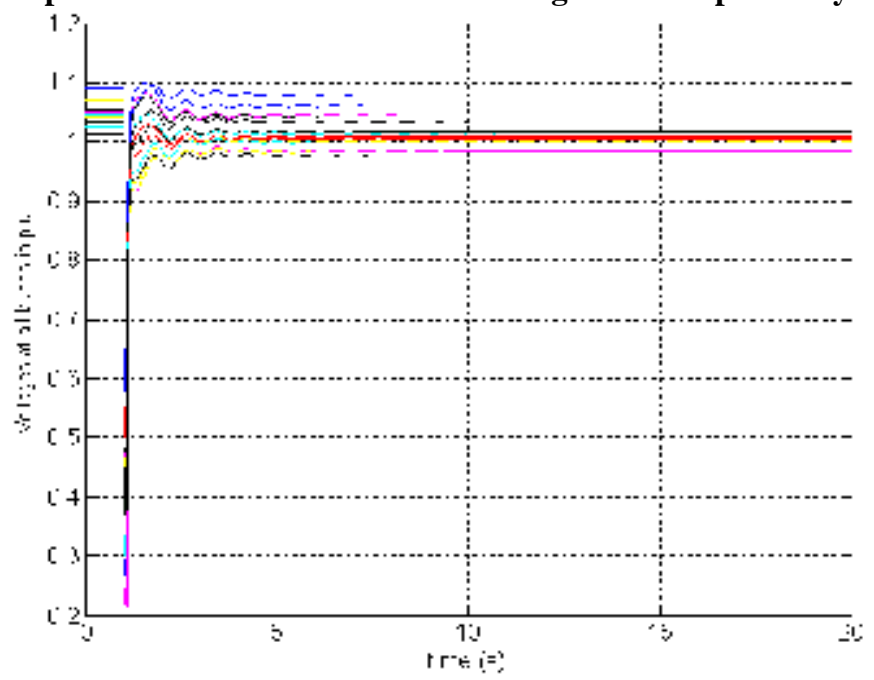

Fig.9 :Voltages at all buses due to line 5-1 outage at $\lambda=1.6$ p.u. for system with (SSSC)

\section{CONCLUSION}

This paper introduces power system stability improvement, by inserting (SSSC) to reduce system losses and congestion of the transmission line, hence increasing maximum load ability of the system. Continuation power flow (CPF) and (LMP)methods were used to find congested line for inserting (SSSC).The simulation results obtained indicated that (SSSC) in congested line will increase maximum loading point in case of normal operating and for two-line outages selected. Also, the time domain simulation show the system dynamic stability performance is improved due to insertion of SSSC).

\section{REFERENCES}

1. Canizares, C.A., (1 February 1995), “Conditions for saddle- node bifurcations in ac/dc power systems," Int. J. of Electric Power \& Energy Systems, vol. 17, pp.:61-68.

2. A. Oudalov, P. Korba, « Coordinated Power Flow Control Using FACTS Device », Corporate Research CH-5405 Baden- DÄattwil,ABB Switzerland Ltd., Switzerland.

3. Preedavinchit P., Srivastava S.C., (1998), "Optimal reactive power dispatch considering FACTS devices", Electric Power Systems Research, Vol. 46, No. 3: 251-257.

4. Huang G., Hsieh S.C., (1998),"Fast textured

Algorithms for optimal delivery problems in deregulated environments", IEEE Trans. on Power Systems, Vol. 13, No. 2: 493-500 
POWER SYSTEM STABILITY IMPROVEMENT USING (SSSC)

5. Momoh, J.A., Zhu J.Z., (1998), “A new approach to optimal power flow with phase shifter”, IEEE International Conference on Systems, Vol. 5: 4794- 4799.

6. Lie T.T., Deng W., (1999), "Optimal flexible AC transmission systems (FACTS) devices allocation", International Journal of Electrical Power and Energy Systems, Vol. 19, No. 2: $125-134$

7. De Oliveira E.J., Lima W.M., (1999), “Allocation of ACTS devices in a competitive environment", 13th PSCC, 1184-1190.

8. F.L. Alvarado,(2005), "Controlling power systems with price signals”, Decision Support Syst. $40495-504$.

9. C.A.Canizares, F.L.Alvardo, C.L.Demarco, I.Dobson, and W. F. Long,(May 1992)," Point of collapse methods applied to ac/dc power systems," IEEE Trans. Power System, vol.7, no.2,pp.673-683.

10. K R Padiyar and K Uma Rao,(1997),"Discrete control of series compensation for stability improvement in power systems", Electrical Power \& Energy Systems, vol. 19, no. 5, pp. 311-319.

11. K.K.Sen,(Jan 1998), "SSSC static synchronous series compensator: theory, modeling, and applications", IEEE Trans. Power Delv., vol. 13, 241-246,

12. H.Taheri, S.Shahabi, Sh.Taheri, A.Gholami, (7/09/2009),"Application of Synchronous Static Series Compensator (SSSC) on Enhancement of voltage Stability and Power Oscillation Damping", 978 -1-4244-3861- IEEE.

13. (Final draft; 1999), "Power system stability subcommittee report on voltage stability assessment, procedures and guides". IEEE/PES,

14. KundurP. (1994):"Power System Stability and Control”, McGraw Hill, New York.

15. SeydelR. (1994):"Practical Bifurcation and Stability Analysis: From Equilibrium to Chaos", Second Edition, Springer-Verlag, New York.

16. Lautenberg M. J., M. A. Pai, and K. R. Padiyar (1997), "Hopf Bifurcation Control in Power System with Static Var Compensators", Int.

17. Hsu M. (1997)“An introduction to the pricing of electric power transmission”, Utilities Policy, 6 (3) :257-270.

18. SrivastavaS.C., R.K. Verma (2000)," Impact of FACTS devices on transmission pricing in a de-regulated electricity market", in: Proceeding of International Conference on Electric Utility Deregulation and Restructuring and Power Technologies (DRPT 2000), April 4-7, City University, London, 2000, pp: 642-648.

19. PSAT Version 2.1.10(2016)Software and Documentation, copyright 2010 Federico Milano. J. Electric Power and Energy Systems, Vol. 19, No.(5):, pp. 339-347,. 